\title{
Genetic diversity increases with depth in red gorgonian populations of the Mediterranean Sea and the Atlantic Ocean
}

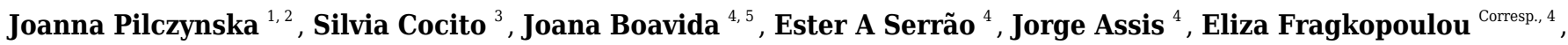 \\ Henrique Queiroga ${ }^{1}$ \\ 1 Departamento de Biologia and CESAM - Centro de Estudos do Ambiente e do Mar, Universidade de Aveiro, Aveiro, Portugal \\ Department of Earth and Environmental Sciences, University of Pavia, Pavia, Italy \\ 3 Italian Agency for New Technologies, Energy and Sustainable Economic Development - ENEA, Marine Environment Research Centre, La Spezia, Italy \\ CCMAR- Centro de Ciências do Mar, Universidade do Algarve, Faro, Portugal \\ 5 Mediterranean Institute of Oceanography - MIO, Aix Marseille Université, Marseille, France \\ Corresponding Author: Eliza Fragkopoulou \\ Email address: efragkopoulou@ualg.pt
}

Background. In the ocean, the variability of environmental conditions found along depth gradients exposes populations to contrasting levels of perturbation, which can be reflected in the overall patterns of species genetic diversity. At shallow sites, resource availability may structure large, persistent and well-connected populations with higher levels of diversity. In contrast, the more extreme conditions, such as thermal stress during heat waves, can lead to population bottlenecks and genetic erosion, inverting the natural expectation. Here we examine how genetic diversity varies along depth for a long-lived, important ecosystem-structuring species, the red gorgonian, Paramuricea clavata.

Methods. We used five polymorphic microsatellite markers to infer differences in genetic diversity and differentiation, and to detect bottleneck signs between shallow and deeper populations across the Atlantic Ocean and the Mediterranean Sea. We further explored the potential relationship between depth and environmental gradients (temperature, ocean currents, productivity and slope) on the observed patterns of diversity by means of generalized linear mixed models.

Results. An overall pattern of higher genetic diversity was found in the deeper sites of the Atlantic Ocean and the Mediterranean Sea. This pattern was largely explained by bottom temperatures, with a linear pattern of decreasing genetic diversity with increasing thermal stress. Genetic differentiation patterns showed higher gene flow within sites (i.e., shallow vs. deeper populations) than between sites. Recent genetic bottlenecks were found in two populations of shallow depths.

Discussion. Our results highlight the role of deep refugial populations safeguarding higher and unique genetic diversity for marine structuring species. Theoretical regression modelling demonstrated how thermal stress alone may reduce population sizes and diversity levels of shallow water populations. In fact, the examination of time series on a daily basis showed the upper water masses repeatedly reaching lethal temperatures for $P$. clavata. Differentiation patterns showed that the deep richer populations are isolated. Gene flow was also inferred across different depths, however, not in sufficient levels to offset the detrimental effects of surface environmental conditions on genetic diversity. The identification of deep isolated areas with high conservation value for the red gorgonian represents an important step in the face of ongoing and future climate changes. 
1 Genetic diversity increases with depth in red gorgonian populations of the Mediterranean

2 Sea and the Atlantic Ocean

3 Joanna Pilczynska ${ }^{1,2}$, Silvia Cocito ${ }^{3}$, Joana Boavida ${ }^{4,5}$, Ester A. Serrão ${ }^{4}$, Jorge Assis ${ }^{4}$, Eliza

4 Fragkopoulou $^{4}$, Henrique Queiroga ${ }^{1}$

$6{ }^{1}$ Departamento de Biologia and CESAM - Centro de Estudos do Ambiente e do Mar,

7 Universidade de Aveiro, 3810-193 Aveiro, Portugal.

8 2Department of Earth and Environmental Sciences, University of Pavia, Strada Nuova, n. 65 9 27100, Pavia, Italy.

10 3'talian Agency for New Technologies, Energy and Sustainable Economic Development 11 ENEA, Marine Environment Research Centre, P.O. Box 224, 19100 La Spezia, Italy.

$12{ }^{4}$ CCMAR - Centro de Ciências do Mar, Universidade do Algarve, 8005-139 Faro, Portugal.

13 5Aix Marseille Université, Mediterranean Institute of Oceanography (MIO) UM 110, 13288

14 Marseille, France.

17 Corresponding author:

18 Eliza Fragkopoulou ${ }^{4}$

20 Email address: efragkopoulou@ualg.pt

21

22

23

24 
27 ABSTRACT

Background. In the ocean, the variability of environmental conditions found along depth gradients exposes populations to contrasting levels of perturbation, which can be reflected in the overall patterns of species genetic diversity. At shallow sites, resource availability may structure large, persistent and well-connected populations with higher levels of diversity. In contrast, the more extreme conditions, such as thermal stress during heat waves, can lead to population bottlenecks and genetic erosion, inverting the natural expectation. Here we examine how genetic diversity varies along depth for a long-lived, important ecosystem-structuring species, the red gorgonian, Paramuricea clavata.

Methods. We used five polymorphic microsatellite markers to infer differences in genetic diversity and differentiation, and to detect bottleneck signs between shallow and deeper populations across the Atlantic Ocean and the Mediterranean Sea. We further explored the potential relationship between depth and environmental gradients (temperature, ocean currents, productivity and slope) on the observed patterns of diversity by means of generalized linear mixed models.

Results. An overall pattern of higher genetic diversity was found in the deeper sites of the Atlantic Ocean and the Mediterranean Sea. This pattern was largely explained by bottom temperatures, with a linear pattern of decreasing genetic diversity with increasing thermal stress. Genetic differentiation patterns showed higher gene flow within sites (i.e., shallow vs. deeper populations) than between sites. Recent genetic bottlenecks were found in two populations of shallow depths.

Discussion. Our results highlight the role of deep refugial populations safeguarding higher and unique genetic diversity for marine structuring species. Theoretical regression modelling demonstrated how thermal stress alone may reduce population sizes and diversity levels of shallow water populations. In fact, the examination of time series on a daily basis showed the upper water masses repeatedly reaching lethal temperatures for $P$. clavata. Differentiation patterns showed that the deep richer populations are isolated. Gene flow was also inferred across different depths, however, not in sufficient levels to offset the detrimental effects of surface 
55

56

57

58

59

60

61

62

63

64

65

66

67

68

69

environmental conditions on genetic diversity. The identification of deep isolated areas with high conservation value for the red gorgonian represents an important step in the face of ongoing and future climate changes.

\section{INTRODUCTION}

Extreme environmental conditions may change the distribution of intra-specific biodiversity (Provan \& Bennett, 2008). However, responses may differ significantly between environments and ecological groups. The trends in genetic diversity of mountain plants and vertebrates along altitudinal gradients are a well-known example, varying from decreased diversity with altitude due to drift and bottlenecks during vertical range expansion, to increased diversity associated with selective pressures at higher altitudes (Giordano, Ridenhour \& Storfer, 2007; Ohsawa \& Ide, 2008).

In the marine environment, environmental gradients are known to affect the genetic diversity levels of the populations (e.g. Costantini 2011; Costantini et al., 2016; Johannesson and André 2006). Particularly, the exposure to limiting niche conditions may reduce population sizes, leading to genetic erosion through bottlenecks and drift (Eckert, Samis \& Lougheed, 2008). Conversely, where conditions are stable for long time, populations may persist and retain ancient genetic diversity (i.e., climatic refugia; Maggs et al., 2008; Provan \& Bennett, 2008). Even small populations of species with reduced dispersal potential may harbour distinct ancient genetic diversity if persisting in refugial areas (e.g., Diekmann \& Serrão, 2012; Assis et al., 2016).

In the coastal zone, depth gradients are associated with increased environmental variability due to the stratification of wind-induced turbulence, light attenuation, nutrient availability, sedimentation and the presence of thermoclines and haloclines (Garrabou, Ballesteros and Zabala, 2002; Assis et al., 2017b). Together, they underpin well-structured gradients of species occurrences, abundances and genetic diversity. While extreme conditions experienced in shallow waters can be detrimental to genetic diversity, deep waters are relatively more stable and can provide genetic refugia (e.g. Smith et al., 2014; Assis et al., 2016). The hypothesis of deep 
83 populations harbouring higher and unique genetic diversity is of great conservational,

84 biogeographical and evolutionary relevance. The loss of such genetically rich populations poses

85 disproportionate risks for the species as a whole, considering the loss of adaptive variation for

86 selection (Hampe \& Petit, 2005). While there is increased evidence of deep populations not

87 being directly affected by events of extreme environmental conditions (e.g. Cerrano et al., 2005;

88 Linares et al., 2005; Smith et al., 2014), these are not immune to disturbances (Bavestrello et al.,

89 2014; Frade et al., 2018). Furthermore, the hypothesis that deeper reefs may be more fecund

90 (Holstein et al., 2015), serving as a source of recruits for the recovery of shallower reefs is

91 controversial between species (Bongaerts et al., 2010, 2017), but also within the same species

92 (Mokhtar-Jamaï et al., 2011; Van Oppen et al., 2011; Pilczynska et al., 2016).

93 The red gorgonian Paramuricea clavata (Risso) lives on shadowed rocky substrates down to 120

$94 \mathrm{~m}$ in the Mediterranean Sea (Salomidi et al., 2009; Bo et al., 2012) and to $100 \mathrm{~m}$ in the Atlantic

95 Ocean (Boavida et al., 2016a). Shallow populations in the Mediterranean have recently suffered massive mortality events caused by thermal stress (Perez et al., 2000; Romano et al., 2000;

97 Garrabou et al., 2009). Damage intensity have been reported to decrease with depth, with 98 communities dwelling below the thermocline of 25 to $30 \mathrm{~m}$ being less affected (Cerrano et al., 2005; Linares et al., 2005). In the Atlantic Ocean, temperature-driven mortality events are presumed to be less frequent as water masses are usually mixed due to summer upwelling (Relvas et al., 2007). However, there are sporadic events of upwelling relaxation, with raising temperatures persisting for several days, responsible for the mortality of shallow water gastropod populations (Lima et al., 2006) and marine forests (Araújo et al., 2016), which eventually may reach levels that could become limiting for the red gorgonian. Here we investigate changes in the genetic diversity levels of $P$. clavata across populations in different depth ranges from the Mediterranean Sea and the Atlantic Ocean. Considering the different potential effect of temperature extremes between different depths, we hypothesize that shallow populations have lower genetic diversity when compared to deeper ones. We further explore the observed patterns of diversity using generalized linear mixed models with environmental information (temperature, current velocity primary productivity and slope). 


\section{MATERIALS \& METHODS}

114 We sampled 2 populations at different depths (shallow vs. deeper) in 3 sites of the Atlantic

115 Ocean (Portuguese coast) and 2 sites of the Mediterranean Sea (Italy coast; Fig. 1; S1) by means

116 of SCUBA diving. Atlantic samples were located between $12 \mathrm{~m}$ and $60 \mathrm{~m}$ depth, while those in

117 the Mediterranean were between $20 \mathrm{~m}$ and $30 \mathrm{~m}$. At each population, $10 \mathrm{~cm}$ apical branches

118 were collected haphazardly from well-separated colonies to avoid clones, as the species can have

119 asexual reproduction, though negligible (Coma, Zabala \& Gili, 1995; Pilczynska et al., 2017).

120 The branch tip from each colony was stored individually in plastic tube underwater and, after

121 transportation to the lab, the samples were preserved in 96\% ethanol until DNA extraction.

122 Sampling permissions for the Mediterranean sites were authorised by Cinque Terre Marine

123 Protected Area and the Regional Natural Park of Porto Venere (Pilczynska et al., 2016). For the

124 Atlantic sites, permission was authorized by the Institution for Conservation of Nature and Forest

125 (ICNF, Portuguese governmental body responsible for the management of Protected Areas).

126 Genomic DNA was extracted with a CTAB protocol (Winnepenninckx, Backeljau \& De

127 Wachter, 1993), using proteinase K, with purification by standard chloroform:isoamyl alcohol

128 (24:1) followed by DNA precipitation. Samples were genotyped at five microsatellite loci: Parcla

129 09, Parcla 10, Parcla 12, Parcla 14, Parcla 17 (Mokhtar-Jamaï et al., 2011). PCR conditions were

130 as described in Mokhtar-Jamaï et al., (2011) with minor modifications (1.5 mM MgCl2, cycle:

$13195^{\circ} \mathrm{C} 3 \mathrm{~min}, 94^{\circ} \mathrm{C} 20 \mathrm{sec}, 45^{\circ} \mathrm{C} 20 \mathrm{sec}, 72^{\circ} \mathrm{C} 20 \mathrm{sec}$ for 40 cycles, final extension $72^{\circ} \mathrm{C} 10 \mathrm{~min}$ ).

132 PCR products were analysed on an ABI 3730XL Genetic Analyser using an internal size

133 standard (GeneScan 600 LIZ; Applied Biosystems). STRand version 2.2.30 was used to score

134 alleles (Locke et al., 2000) and the R package MsatAllel_1.02 (Alberto, 2009) allowed to

135 visualise, track and reanalyse putative scoring errors.

136 Additional genetic data for the same microsatellite loci were compiled from Mokhtar-Jamaï et al.

137 (2011). Extra sites were chosen when comprising 2 populations at different depths (shallow vs.

138 deeper). The new data (5 sites) were located in the Spanish and French Mediterranean coasts,

139 between $15 \mathrm{~m}$ and $40 \mathrm{~m}$ depth (Fig. 1; S1).

140 The shallow and deeper populations sampled in the Atlantic and Mediterranean do not coincide

141 with the same exact depths, as vertical distribution limits varied between sites. Thus, 
142 comparisons of genetic diversity levels between shallow and deeper populations were made at

143 the site scale, and not between sites. Allelic richness, number of private alleles and gene diversity

144 (expected heterozygosity) per population (shallow and deeper) were standardized to the smallest

145 sample size found within sites using $10^{4}$ randomizations. Significant differences in mean

146 diversity levels within each site were tested using a non-parametric Wilcoxon signed-rank test

147 with $10^{4}$ randomizations (Assis et al., 2018).

148 To infer the drivers shaping genetic variation among sites, genetic diversity estimates were 149 standardized to the smallest size of all samples using $10^{4}$ randomizations. The estimates of 150 diversity were modelled with linear regression against depth (null model) and a set of important 151 environmental predictors affecting the physiology of $P$. clavata (Maximum bottom temperature;

152 Boavida et al., 2016b) and proxies of essential resources (minimum bottom productivity, 153 minimum bottom current velocity and slope, for food intake; Boavida et al., 2016b). Other 154 important predictors were not considered since (1) they did not vary between sampling sites 155 (e.g., salinity) or (2) were correlated with productivity (e.g., inorganic nutrients such as nitrates 156 and phosphates). The predictors were developed with three-dimensional profiles of monthly data 157 compiled from the Global Ocean Physics Reanalysis (ORAP; www.marine.copernicus.eu) and 158 the Biogeochemistry Non-Assimilative Hindcast Simulation (PISCES;

159 www.marine.copernicus.eu). Bottom environmental data for each population was obtained using 160 trilinear interpolation (Assis et al., 2017b) weighting location (longitude and latitude) and depth.

161 Long-term minimum (productivity and currents) and maximum (temperature) extremes were 162 averaged for the years 2000-2014. Slope was computed using the "terrain" function of the R 163 package "raster" (3.5.2 version; R Foundation for Statistical Computing, 2018) in bathymetry.

164 Given the sampling design (no precise coincidence of depths between sites) we adopted the 165 Generalized Linear Mixed Models (GLMM; Bolker et al., 2009) framework. This is suitable for 166 modelling unbalanced designs (Zhang and Chen, 2013) and complex spatial and temporal 167 correlation structures since it accounts for dependencies within hierarchical groups by 168 introducing random effects (Bolker et al., 2009). While these effects generally comprise the

169 blocking in experimental treatments, they can be used to encompass variation among

170 geographical regions (Dormann et al., 2007). Accordingly, "site" was included in the models as a 171 random effect term (Zuur, Ieno and Smith, 2007; Ludwig et al., 2012). The best-fit selection 
172 between the null and the environmental models followed the relative Akaike Information

173 Criterion (AIC), while goodness-of-fit was inferred with the R2GLMM algorithm from Edwards

174 et al. (2008). Partial dependence plots were also produced to illustrate the effect of predictors on

175 the response of models, by accounting for the mean effect of all other predictors (Elith,

176 Leathwick and Hastie, 2008). All models were performed in the R environment (3.5.2 version; R

177 Foundation for Statistical Computing, 2018).

178 To infer larval dispersal potential, pairwise genetic differentiation was estimated between and

179 within sampled populations (i.e., shallow vs. deeper populations) using $F_{\mathrm{ST}}$ estimator and an

180 analysis of molecular variance (AMOVA) based on allele frequencies, computed with Genodive

181 (Meirmans and Van Tienderen, 2004) under 104 randomizations (Assis et al., 2013).

182 Evidence of genetic bottlenecks were inferred by testing for heterozygosity excess (Piry, Luikart

183 and Cornuet, 1999). This is rooted on the assumption that populations that have recently

184 experienced a bottleneck event are predicted to temporarily reduce allelic diversity at a faster rate

185 than heterozygosity. Such an excess in heterozygosity rate was tested for each population with

186 the software Bottleneck (Piry, Luikart and Cornuet, 1999) using $10^{4}$ simulations. We used the

187 suggested and more appropriate (realistic) parameters for microsatellites: the Two-Phase Model

188 (TPM) (Luikart and Cornuet, 1998; Piry, Luikart and Cornuet, 1999) with a step in mutations of

1890.9 (ps) and a variance in mutations of 12 (Piry, Luikart and Cornuet, 1999; Busch, Waser and

190 DeWoody, 2007). Because the genetic dataset has less than 20 loci, we used the Wilcoxon test to

191 address the null hypothesis of no heterozygosity excess (on average) across loci (Cornuet and

192 Luikart, 1996; Luikart and Cornuet, 1998).

193

194

195 RESULTS

196 Genetic diversity as allelic richness (A) and number of private alleles (PA) was consistently

197 higher in deeper populations, with the exception of only one site (Petit Congloue; Fig 2a.b). The

198 greatest difference in A and PA between shallow and deeper populations was observed in

199 Pharillions and Sagres (A: 2.7 and 2.07; PA: 13.52 and 10.33, respectively), while the smallest 
200 was observed in Livorno (A: 0.09 and PA: 0.43). The variation in expected heterozygosity (He)

201 did not follow a clear pattern, with only one sampling site (Grotte Peres) having a higher He in

202 its deeper population (Fig 2c).

203 The null linear regression models using depth alone were outperformed by the models using 204 environmental predictors (environmental models showed lower AIC and higher R²; Table 1).

205 Both approaches found significant relationships while fitting the predictors against standardized 206 allelic richness and number of private alleles (Table 1), however, they failed to explain the 207 variability in expected heterozygosity. The environmental models showing better fitting were 208 mostly explained by temperature alone (Table 1). This predictor produced a negative response on 209 the models, with lower allelic richness and private alleles with increasing bottom temperatures 210 (Fig 3).

211 Genetic differentiation $\left(F_{\mathrm{ST}}\right)$ was higher between than within sampling sites, with two exceptions

212 for Sagres and Riou Sud (Fig 4). The former site (i.e., Sagres) showed the highest differentiation

213 of all pairwise comparisons at the site scale (i.e., shallow vs. deeper sample; $F_{\mathrm{ST}} \approx 0.4 ; \mathrm{S} 2$ ). No

214 significant differentiation was found within 7 Mediterranean sites (Punta Mesco, Livorno, Pota

215 Del Llop, Grotte Peres and Petit Congloue; S2) and between the two populations of Grotte Peres

216 and the deeper population of Petit Congloue (S2), which are approximately $2 \mathrm{~km}$ far apart.

217 Bottleneck events (heterozygosity excess) were detected in the shallow populations of Berlengas 218 and Punta Mesco (Table 1; S3). All remaining populations showed no heterozygosity excess (on 219 average) across loci (Table 1; S3).

220

221

\section{DISCUSSION}

223 The distribution of genetic diversity corroborated the expectations associating extreme

224 environmental changes with the reduction of effective population sizes and genetic diversity 225 levels (Garrabou et al., 2009). Our model species $P$. clavata consistently showed less allelic 226 richness, a smaller number of private alleles and bottleneck signs (for two sites) in shallow 227 waters populations. This pattern found across the Atlantic Ocean and Mediterranean Sea was 228 explained by the negative relationship between thermal stress and depth, and not by the proxies 
229

230

231

232

233

234

235

236

237

238

239

240

241

242

243

244

245

246

247

248

249

250

251

252

253

254

255

256

257

258

259

used of essential resources (i.e., productivity, current velocity and slope). In fact, the examination of daily time series of bottom temperatures for each site and depth range (S4) shows shallow water masses recurrently surpassing the physiological threshold of $24-25^{\circ} \mathrm{C}$ from which mortality occurs (Previati et al., 2010; Pairaud et al., 2014; Boavida et al., 2016b), particularly in the Mediterranean Sea. This is in line with previous studies linking mass-mortality events of $P$. clavata with marine heatwaves, which reported increased mortality in more shallow environments (Cerrano et al., 2005; Linares et al., 2005). Still, the observed differences in genetic diversity may have resulted from additional factors beyond temperature changes, not considered in our study. For instance, the scarcity of favourable rocky bottoms may strongly reduce population sizes of $P$. clavata (Linares et al., 2008; Boavida et al., 2016b). This could be a plausible explanation for the one exception found in the diversity levels of deep populations. The lower diversity in the deeper population of Petite Congloue may result from a smaller and patchier distribution of individuals, if the availability of rocky bottoms is limited. In a particular survey, Gori et al. (2011) found the density of $P$. clavata decreasing with depth, as populations were highly dependent on the presence of rocky vertical walls in shallower waters. In our study, the availability of rocky bottoms was not considered, although slope may be considered as a proxy for such environmental factor at biogeographical scales (e.g. Boavida et al., 2016b), it might not have reflected site scale habitat changes between our sampling depths. Further, competition with other species, such as photosynthetic algae (Zabala and Ballesteros, 1989), together with higher hydrodynamics regimes and human induced disturbances (e.g. anchoring, scuba diving), may further help explaining the overall pattern found, restricting large, continuous and richer populations to deeper sites (Harmelin and Marinopoulos, 1994; Cúrdia et al., 2013).

Contrarily to allelic richness and number of private alleles, gene diversity (i.e., expected heterozygosity) did not correlated with depth, nor with the additional predictors considered in regression analyses. Gene diversity is not as sensitive as allelic richness to detecting historical population changes (Leberg, 1992; Petit, Mousadik \& Pons, 1998; Spencer et al., 2000) since drift resulting from population size reductions theoretically affects more the rare alleles than the frequent ones (Nei, Maruyama \& Chakraborty, 1975). Accordingly, the diversity pattern found in deeper populations implies persistence without significant population reduction, raising the hypothesis of deep refugia for P. clavata. These cryptic populations may play an important role in buffering the loss of diversity in shallow waters, as reported for other corals (Bongaerts et al., 
260 2010, 2017; Smith et al., 2014). Similar to terrestrial elevational refugia, the stability of deep 261 environments may be an important mechanism safeguarding regional genetic diversity for the 262 species as a whole (Epps et al., 2006; Assis et al., 2016; Lourenço et al., 2016).

263 While diversity levels of $P$. clavata followed the patterns of thermal stress, the bottleneck tests 264 did not provide a strong empirical support of recent bottlenecks in shallow populations

265 (exceptions for Berlengas e Punta Mesco). Although recent environmental changes may account 266 for genetic diversity losses, the fluctuations of past climate changes may further shape the 267 genetic structure of marine species, both latitudinally and along depth gradients (Maggs et al., 268 2008; Provan 2013; Assis et al., 2014; 2016; 2018; Neiva et al., 2016). The lower diversity 269 found in shallow populations could have resulted from past climate extremes, an historical effect 270 that cannot be detected with tests based on heterozygosity excess (Peery et al., 2012). Also, one 271 cannot discard the limited statistical power of these tests when using small sample sizes, as in 272 our case (small number of individuals and loci; Piry et al., 1999; Peery et al., 2012). Our 273 approach could have overlooked actual population declines. For instance, previous studies on $P$. 274 clavata, with similar sample sizes, drew unambiguous conclusions by failing to detect 275 bottlenecks in populations that actually suffered mass-mortality events (Pilczynska et al., 2016;

276 Padron et al., 2018).

277 Population differentiation was found higher between than within sampled sites. This is in line 278 with the low dispersal potential of the species, posing highly structured gene pools throughout 279 the Atlantic Ocean and the Mediterranean Sea (Linares et al., 2007; Mokhatar-Jamai et al., 2011; 280 Pilczynska et al., 2016; Padrón et al., 2018). At the site scale, the non-significant differentiation 281 levels (Punta Mesco, Livorno, Pota Del Llop, Grotte Peres and Petit Congloue) suggest that gene 282 flow and admixture occurs along depth ranges. While summer thermoclines were thought to be a 283 major force structuring genetic diversity of gorgonian species (Constantini 2011; Constantini et 284 al., 2016), our results do not support such hypothesis. The shallow populations of $P$. clavata 285 harbouring lower diversity levels are not in complete isolation from those in deep richer areas, as 286 previously suggested for the species (Cerrano and Bavestrello, 2008). However, contrasting 287 patterns of coral gene flow can occur across different environments (e.g. Van Oppen et al., 2011; 288 Mokhtar-Jamai et al., 2011; Pilczynska et al., 2016). For instance, the higher within site 289 differentiation in Sagres can result from the alongshore coastal circulation regime in the Gulf of 
290 Cadiz that extends to the Sagres region (Garel et al., 2016), promoting high connectivity levels

291 along deep neighbouring populations, or from the fact that the shallow population of Sagres was

292 located within a cave, possibly, further hindering connectivity. This was an exception though, as

293 the overall connectivity pattern found is one of restricted connectivity between deeper

294 populations. Thus, their diversity levels may have resulted from persistence alone, and not by

295 admixture processes, as also suggested by the number of private alleles. The differentiation

296 pattern further allows concluding that connectivity along depth ranges (within site) does not

297 seem to completely offset the more detrimental effects occurring in shallow water populations,

298 reducing genetic diversity of $P$. clavata, as observed.

299 Our findings of deep isolated richer populations have significant conservation value for the

300 species as a whole. Future environmental changes are predicted to produce a major redistribution

301 of marine biodiversity in the Atlantic Ocean and the Mediterranean Sea (Albouy et al., 2013;

302 Assis et al., 2017a), particularly in the business as usual climate scenario (RCP8.5; Assis et al.,

303 2017). The reduction of biodiversity through the loss of rich and distinct gene pools found in

304 deep populations may contribute to the loss of genes responsible for the species adaptation and

305 evolution (Hughes \& Stachowicz 2004; Hampe \& Petit, 2005; Reusch et al., 2005). The

306 identified genetically rich populations of $P$. clavata represent an important baseline for Climate

307 Change Integrated Conservation Strategies for phylogeographic lineages (Hannah, Midgley and

308 Millar, 2002).

309

310 CONCLUSIONS

311 This study demonstrates that deeper marine populations can consistently harbour higher genetic

312 diversity than those in shallower environments. Theoretical regression modelling using

313 environmental data showed that such genetic pattern may arise from thermal stress alone,

314 reducing population sizes and diversity levels. These findings raised the hypothesis of deep

315 refugia for $P$. clavata, with deeper populations in more stable environments safeguarding the

316 species biodiversity across the Mediterranean and Atlantic populations. In fact, the analyses of

317 temperature time-series showed shallow populations exposed to temperatures surpassing the

318 species thermal tolerance, often for as long as over 2 months, while deep populations were 
319 almost never exposed to such conditions. The patterns of population differentiation revealed that

320 gene flow occurs between shallow and deeper populations, although not in sufficient levels to

321 homogenise depth differences in diversity levels. Empirical evidence is provided for deep

322 persistent populations of gorgonians with the potential to safeguard richer and unique gene pools.

323 While additional genetic data could better support the major findings, particularly by increasing

324 the power of bottleneck tests (more molecular markers and sampling sites), this study represents

325 a timely baseline to conserve populations with higher conservation value in risk of disappearing.

\section{REFERENCES}

329 Alberto, F. (2009) 'MsatAllele-1.0: An R package to visualize the binning of microsatellite 330 alleles', Journal of Heredity, 100, 394-397.

331 Albouy C, Guilhaumon F, Leprieur F, Lasram FBR, Somot S, Aznar R, Velez L, Le Loch F, 332 Mouillot D. (2013). Projected climate change and the changing biogeography of coastal

333 Mediterranean fishes. Journal of Biogeography, 40, 534-547.

334 Araújo RM, Assis J, Aguillar R, Airoldi L, Bárbara I, Bartsch I, Bekkby T, Christie H, Davoult 335 D, Derrien-Courtel S, Fernandez C, Fredriksen S, Gevaert F, Gundersen H, Le Gal A, Lévêque 336 L, Mieszkowska N, Norderhaug KM, Oliveira P, Puente A, Rico JM, Rinde E, Schubert H, 337 Strain EM, Valero M, Viard F, Sousa-Pinto I. (2016). Status, trends and drivers of kelp forests in 338 Europe: an expert assessment. Biodiversity and Conservation, 25, 1319-1348.

339 Assis, J., Castilho Coelho, N., Alberto, F., Valero, M., Raimondi, P., Reed, D., \& Alvares Serrão, 340 E. (2013) High and Distinct Range-Edge Genetic Diversity despite Local Bottlenecks. PLoS 341 ONE, 8, 1-11.

342 Assis, J., Serrão, E. A., Claro, B., Perrin, C., \& Pearson, G. A. (2014). Climate-driven range

343 shifts explain the distribution of extant gene pools and predict future loss of unique lineages in a 344 marine brown alga. Molecular Ecology, 23, 2797-2810. 
346 Assis J, Coelho NC, Lamy T, Valero M, Alberto F, Serrão EA. (2016). Deep reefs are climatic

347 refugia for genetic diversity of marine forests. Journal of Biogeography, 43, 833-844.

348 Assis J, Araújo BM, Serrão EA. (2017a). Projected climate changes threaten ancient refugia of

349 kelp forests in the North Atlantic. Global Change Biology, 24, e55-e66.

350 Assis J, Tyberghein L, Bosch S, Verbruggen H, Serrão EA, De Clerck O. (2017b). Bio-

351 ORACLE v2.0: Extending marine data layers for bioclimatic modelling. Global Ecology and

352 Biogeography, 27, 277-284.

353 Assis, J., Álvares, E., Nelson, S., Coelho, C., Tempera, F., Valero, M., \& Alberto, F. (2018) Past

354 climate changes and strong oceanographic barriers structured low - latitude genetic relics for the 355 golden kelp Laminaria ochroleuca. Journal of Biogeography, 45, 2326-2336.

356 Bavestrello, G., Bo, M., Canese, S., Sandulli, R., \& Cattaneo-Vietti, R. (2014) The red coral

357 populations of the gulfs of Naples and Salerno: human impact and deep mass mortalities. Italian

358 Journal of Zoology, 81, 552-563.

359 Bo, M., Canese, S., Spaggiari, C., Pusceddu, A., Bertolino, M., Angiolillo, M., Giusti, M.,

360 Loreto, M.F., Salvati, E., Greco, S., \& Bavestrello, G. (2012) Deep Coral Oases in the South

361 Tyrrhenian Sea. PLoS ONE, 7, e49870.

362 Boavida J, Paulo D, Aurelle D, Arnaud-Haound S, Marschal C, Gonçalves JMS, Serrão EA

363 (2016a) A well-kept treasure at depth: Precious red coral rediscovered in Atlantic deep coral

364 gardens (SW Portugal) after 300 years. PLoS ONE, 11, e0150654.

365 Boavida J, Silva I, Assis J, Serrão EA. (2016b). Overlooked habitat of a vulnerable gorgonian

366 revealed in the Atlantic and Mediterranean by niche modelling. Scientific Reports, 6, 36460.

367 Bolker, B.M., Brooks, M.E., Clark, C.J., Geange, S.W., Poulsen, J.R., Stevens, M.H.H., \&

368 White, J.S.S. (2009) Generalized linear mixed models: a practical guide for ecology and

369 evolution. Trends in Ecology and Evolution, 24, 127-135.

370 Bongaerts, P., Ridgway, T., Sampayo, E.M., \& Hoegh-Guldberg, O. (2010) Assessing the "deep

371 reef refugia” hypothesis: Focus on Caribbean reefs. Coral Reefs, 29, 1-19. 
372 Bongaerts, P., Riginos, C., Brunner, R., Englebert, N., Smith, S.R., \& Hoegh-Guldberg, O.

373 (2017) Deep reefs are not universal refuges: Reseeding potential varies among coral species.

374 Science Advances, 3, e1602373.

375 Busch, J.D., Waser, P.M., \& DeWoody, J.A. (2007) Recent demographic bottlenecks are not

376 accompanied by a genetic signature in banner-tailed kangaroo rats (Dipodomys spectabilis).

377 Molecular Ecology, 16, 2450-2462.

378 Cerrano C, Arillo A, Azzini F, Calcinai B, Castellano L, Muti C, Valisano L, Zega G,

379 Bavestrello G. (2005). Gorgonian population recovery after a mass mortality event. Aquatic

380 Conservation, 15, 147-157.

381 Cerrano, C. \& Bavestrello, G. (2008) Medium-term effects of die-off of rocky benthos in the

382 Ligurian Sea. What can we learn from gorgonians? Chemistry and Ecology, 24, 73-82.

383 Coma R, Zabala M, Gili JM. (1995). Sexual reproductive effort in the Mediterranean gorgonian

384 Paramuricea clavata. Marine Ecology Progress Series, 117, 185-192.

385 Cornuet, J.M. \& Luikart, G. (1996) Description and power analysis of two tests for detecting recent population

386 bottlenecks from allele frequency data. Genetics, 144, 2001-2004.

387 Costantini, F. (2011) Low connectivity and declining genetic variability along a depth gradient in Corallium

388 rubrum populations. Coral Reefs, 30, 991-1003.

389 Costantini, F., Gori, A., Lopez-González, P., Bramanti, L., Rossi, S., Gili, J.M., \& Abbiati, M.

390 (2016) Limited genetic connectivity between gorgonian morphotypes along a depth gradient.

391 PLOS ONE, 11, 1-20.

392 Cúrdia, J., Monteiro, P., Afonso, C.M.L., Santos, M.N., Cunha, M.R., \& Gonçalves, J.M.S.

393 (2013) Spatial and depth-associated distribution patterns of shallow gorgonians in the Algarve

394 coast (Portugal, NE Atlantic). Helgoland Marine Research, 67, 521-534.

395 Diekmann OE, Serrão EA. (2012). Range-edge genetic diversity: Locally poor extant south

396 southern patches maintain a regionally diverse hotspot in the seagrass Zostera marina. Molecular

397 Ecology, 21, 1647-1657. 
398 Dormann C. F., McPherson J. M., Araújo M. B., Bivand R., Bolliger J., Carl G, Davies R. G., Hirzel A., Jetz

399 W., Kissling D. W., Kühn I., Ohlemüller R., Peres-Neto P. R., Reineking B., Schröder B., Schurr F. M. \&

400 Wilson, R. (2007) Methods to account for spatial autocorrelation in the analysis of species distributional data:

401 A review. Ecography, 30, 609-628.

402 Edwards, L.J., Muller, K.E., Wolfinger, R.D., Qaqish, B.F., \& Schabenberger, O. (2008) An R2 statistic for

403 fixed effects in the linear mixed model. Statistics in Medicine, 27, 6137-6157.

404 Elith, J., Leathwick, J.R., \& Hastie, T. (2008) A working guide to boosted regression trees. Journal of Animal 405 Ecology, 77, 802-813.

406 Eckert CG, Samis KE, Lougheed SC. (2008). Genetic variation across species’ geographical

407 ranges: The central-marginal hypothesis and beyond. Molecular Ecology, 17, 1170-1188.

408 Epps CW, Palsboll PJ, Wehausen JD, Roderick GK, McCullough DR. (2006). Elevation and 409 connectivity define genetic refugia for mountain sheep as climate warms. Molecular Ecology, 410 15, 4295-302.

411

412 Frade, P.R., Bongaerts, P., Englebert, N., Rogers, A., Gonzalez-Rivero, M., \& Hoegh-Guldberg, 413 O. (2018) Deep reefs of the Great Barrier Reef offer limited thermal refuge during mass coral 414 bleaching. Nature Communications, 9, 1-8.

415

416 Garel, E., Laiz, I., Drago, T., \& Relvas, P. (2016) Characterisation of coastal counter-currents on 417 the inner shelf of the Gulf of Cadiz. Journal of Marine Systems, 155, 19-34.

418

419 Garrabou, J., Ballesteros, E., \& Zabala, M. (2002) Structure and dynamics of north-western Mediterranean 420 rocky benthic communities along a depth gradient. Estuarine, Coastal and Shelf Science, 55, 493-508.

421 Garrabou J, Coma R, Bensoussan N, Chevaldonné P, Cigliano M, Diaz D, Harmelin LG, Gambi 422 MC, Kerstingk DK, Ledoux JB, Lejeusne C, Linares C, Marschal C, Pérez T, Ribes M, Romano 423 JC, Serrano E, Teixido N, Torrents O, Zabala M, Zuberer F, Cerrano C. (2009). Mass mortality 424 in NW Mediterranean rocky benthic communities: effects of the 2003 heat wave. Global Change 425 Biology, 15, 1090-1103. 
426 Giordano AR, Ridenhour BJ, Storfer A. (2007). The influence of altitude and topography on 427 genetic structure in the long-toed salamander (Ambystoma macrodactulym). Molecular Ecology, $428 \quad 16,1625-1637$.

429 Hampe A, Petit Rj. (2005). Conserving biodiversity under climate change: The rear edge matters. 430 Ecology Letters, 8, 461-467.

431 Hannah, L., Midgley, G.F., \& Millar, D. (2002) Climate change-integrated conservation strategies. Global 432 Ecology and Biogeography, 11, 485-495.

433 Harmelin, J.-G. \& Marinopoulos, J. (1994) Population structure and partial mortality of the gorgonian 434 Paramuricea clavata (Risso) in the north-western Mediterranean (France, Port-Cros Island). Marine Life, 4, 543513.

436 Holstein, D.M., Smith, T.B., Gyory, J., \& Paris, C.B. (2015) Fertile fathoms: Deep reproductive refugia for 437 threatened shallow corals. Scientific Reports, 5, 1-12.

438 Hughes AR, Stachowicz JJ. (2004). Genetic diversity enhances the resistance of a seagrass 439 ecosystem to disturbance. Proceedings of the National Academy of Sciences of the United States 440 of America, 101, 8998-9002.

441 Johannesson, K. \& André, C. (2006) Life on the margin: genetic isolation and diversity loss in a 442 peripheral marine ecosystem, the Baltic Sea. Molecular Ecology, 15, 2013-2029.

443 Leberg PL. (1992). Effects of population bottlenecks on genetic diversity as measured by 444 allozyme electrophoresis. Evolution, 46, 477-494.

445 Lima FP, Queiroz N, Ribeiro PA, Hawkins SJ, Santos AM. (2006). Recent changes in the 446 distribution of a marine gastropod, Patella rustica Linnaeus, 1758, and their relationship to 447 unusual climatic events. Journal of Biogeography, 33, 812-822.

448 Linares C, Coma R, Diaz D, Zabala M, Hereu B, Dantart L. (2005). Immediate and delayed 449 effects of a mass mortality event on gorgonian population dynamics and benthic community 450 structure in the NW Mediterranean Sea. Marine Ecology Progress Series, 305, 127-137, 
451 Linares C, Doak DF, Coma R, Díaz D, Zabala M. (2007). Life history and viability of a long452 lived marine invertebrate: the octocoral Paramuricea clavata. Ecology. 88, 918-928.

453 Linares, C., Coma, R., Garrabou, J., Díaz, D., \& Zabala, M. (2008) Size distribution, density and 454 disturbance in two Mediterranean gorgonians: Paramuricea clavata and Eunicella singularis. 455 Journal of Applied Ecology, 45, 688-699.

456 Locke M, Baack E, Toonen R. (2000). STRand. Version 2.2.30. Veterinary Genetics Lab. 457 University of California, Davis, CA.

458 Lourenço CR, Zardi GI, McQuaid CD, Serrão EA, Pearson GA, Jacinto R, Nicastro KR. 459 (2016). Upwelling areas as climate change refugia for the distribution and genetic diversity of 460 a marine macroalga. Journal of Biogeography, 43, 1595-1607.

461

462 Ludwig, M., Schlinkert, H., Holzschuh, A., Fischer, C., Scherber, C., Trnka, A., Tscharntke, T., \& Batáry, P. 463 (2012) Landscape-moderated bird nest predation in hedges and forest edges. Acta Oecologica, 45, 50-56.

464 Luikart, G. \& Cornuet, J.M. (1998) Empirical evaluation of a test for identifying recently 465 bottlenecked populations from allele frequency data. Conservation Biology, 12, 228-237. 466

467 Maggs, C.A., Castilho, R., Foltz, D., Henzler, C., Jolly, M.T., Kelly, J., Olsen, J., Perez, K., 468 Stam, W., Vainola, R., Viard, F., \& Wares, J. (2008) Evaluating Signatures of Glacial Refugia 469 for North Atlantic Marine Organisms. Ecology, 89, S108-S122.

470 Meirmans, P.G. \& Van Tienderen, P.H. (2004) GENOTYPE and GENODIVE: Two programs 471 for the analysis of genetic diversity of asexual organisms. Molecular Ecology Notes, 4, $792-794$.

472 Mokhtar-Jamaï K, Pascual M, Ledoux Jb, Coma R, Féral Jp, Garrabou J, Aurelle D. (2011). 473 From global to local genetic structuring in the red gorgonian Paramuricea clavata: The interplay 474 between oceanographic conditions and limited larval dispersal. Molecular Ecology, 20, 32914753305.

476 Nei M, Maruyama T, Chakraborty R. (1975). The bottleneck effect and genetic variability in 477 populations. Evolution 29, 1-10. 
478 Neiva, J., Serrão, E., Assis, J., Pearson, G., Coyer, J., Olsen, J., ...Valero,M. (2016). Climate 479 oscillations, range shifts and phylogeographic pat-terns of North Atlantic Fucaceae. In Z.-M. Hu, 480 \& C. Fraser (Eds.), Sea-weed phylogeography (pp. 279-308). Netherlands: Springer.

481 Ohsawa T, Ide Y. (2008). Global patterns of genetic variation in plant species along vertical and 482 horizontal gradients on mountains. Global Ecology and Biogeography, 17, 152-163.

483 Padrón, M., Costantini, F., Bramanti, L., Guizien, K., \& Abbiati, M. (2018) Genetic connectivity 484 supports recovery of gorgonian populations affected by climate change. Aquatic Conservation: 485 Marine and Freshwater Ecosystems, 28, 776-787.

486 Pairaud, I.L., Bensoussan, N., Garreau, P., Faure, V., \& Garrabou, J. (2014) Impacts of climate change on 487 coastal benthic ecosystems: assessing the current risk of mortality outbreaks associated with thermal stress in 488 NW Mediterranean coastal areas. Ocean Dynamics, 64, 103-115.

489 Peery Z., M., Kirby, R., Reid, B.N., Stoelting, R., Doucet-Bëer, E., Robinson, S., Vásquez-Carrillo, C., Pauli, 490 J.N., \& Palsboll, P.J. (2012) Reliability of genetic bottleneck tests for detecting recent population declines. 491 Molecular Ecology, 21, 3403-3418.

492 Perez T, Garrabou J, Sartoretto S, Harmelin JG, Francour P, Vacelet J. (2000). Mass mortality of 493 marine invertebrates: an unprecedented event in the Northwestern Mediterranean. Comptes 494 Rendus de l'Académie des Sciences Paris, 323, 853-865.

495 Petit RJ, El Mousadik A, Pons O. (1998). Identifying populations for conservation on the basis 496 of genetic markers. Conservation Biology, 12, 844-855.

497 Pilczynska J, Cocito S, Boavida J, Serrão E, Queiroga H. (2016). Genetic Diversity and Local 498 Connectivity in the Mediterranean Red Gorgonian Coral after Mass Mortality Events. PLoS 499 ONE, 11, e0150590.

500 Pilczynska J, Boavida J, Cocito S, Lombardi C, Peirano A, Queiroga H. (2017). Low clonal 501 propagation in Atlantic and Mediterranean populations of the red gorgonian Paramuricea 502 clavata (Octocorallia). Scientia Marina, 81,103-110.

503 Piry, S., Luikart, G., \& Cornuet, J.M. (1999) BOTTLENECK: A computer program for detecting recent 504 reductions in the effective population size using allele frequency data. Journal of Heredity, 90, 502-503. 
505 Previati, M., Scinto, A., Cerrano, C., \& Osinga, R. (2010) Oxygen consumption in

506 Mediterranean octocorals under different temperatures. Journal of Experimental Marine Biology

507 and Ecology, 390, 39-48.

508 Provan J, Bennett KD. (2008). Phylogeographic insights into cryptic glacial refugia. Trends in

509 Ecology and Evolution, 23, 564-571.

510 Provan, J. (2013). The effects of past, present and future climate changeon range-wide genetic

511 diversity in northern North Atlantic marinespecies. Frontiers of Biogeography, 5, 60-66.

512 Relvas P, Barton ED, Dubert J, Oliveira PB, Peliz A, Da Silva JCB, Santos AMP. (2007).

513 Physical oceanography of the western Iberia ecosystem: latest views and challenges. Progress

514 Oceanography, 74, 149-173,

515 Reusch TB, Ehlers A, Hämmerli A, Worm B. (2005). Ecosystem recovery after climatic

516 extremes enhanced by genotypic diversity. Proceedings of the National Academy of Sciences of

517 the United States of America, 102, 2826-2831.

518 Romano JC, Bensoussan N, Younes WA, Arlhac D. (2000). Anomalie thermique dans les eaux

519 du golfe de Marseille durant l'été 1999. Une explication partielle de la mortalité d'invertébrés

520 fixés? Comptes Rendus de l'Académie des Sciences-Series III-Sciences de la Vie, 323, 415-427.

521 Salomidi, M., Smith, C., Katsanevakis, S., Panayotidis, P., \& Papathanassiou, V. (2009) Some

522 observations on the structure and distribution of Gorgonian assemblages in the Eastern

523 Mediterranean Sea. Proceedings of the 1st symposium on conservation of the coralligenous bio-

524 concretions (Tabarka 16-19 January), 242-245.

525 Smith TB, Glynn PW, Maté JL, Toth LT, Gyory J. (2014). A depth refugium from catastrophic

526 coral bleaching prevents regional extinction. Ecology, 95, 1663-1673.

527 Spencer CC, Neigel JE, Leberg PL. (2000). Experimental evaluation of the usefulness of

528 microsatellite DNA for detecting demographic bottlenecks. Molecular Ecology, 9, 1517-1528.

529 Van Oppen, M.J.H., Bongaerts, P., Underwood, J.N., Peplow, L.M., \& Cooper, T.F. (2011) The

530 role of deep reefs in shallow reef recovery: An assessment of vertical connectivity in a brooding

531 coral from west and east Australia. Molecular Ecology, 20, 1647-1660. 
532 Winnepenninckx B, Backeljau T, De Wachter R. (1993). Extraction of high molecular weight 533 DNA from molluscs. Trends in Genetics 9, 407.

534 Zabala, M. \& Ballesteros, E. (1989) Surface-dependent strategies and energy flux in benthic marine 535 communities or, why corals do not exist in the Mediterranean. Scientia Marina, 53, 3-17.

536 Zhang, G. \& Chen, J.J. (2013) Adaptive Fitting of Linear Mixed-Effects Models with Correlated Random537 effects. Journal of statistical computation and simulation, 83, 2291-2314.

538 Zuur, A.F., Ieno, E.N., \& Smith, G.M. (2007) Analyzing Ecological Data. Springer- Verlag New 539 York. 
Figure 1

Sampling sites of the red gorgonian (Paramuricea clavata) populations in the Atlantic Ocean and the Mediterranean Sea. The exact coordinates of each sampling site are available in the supplementary information (S1).

Map source "๑OpenStreetMap contributors", available under the Open Database License. This figure is published under CC BY SA, https://www.openstreetmap.org/copyright .

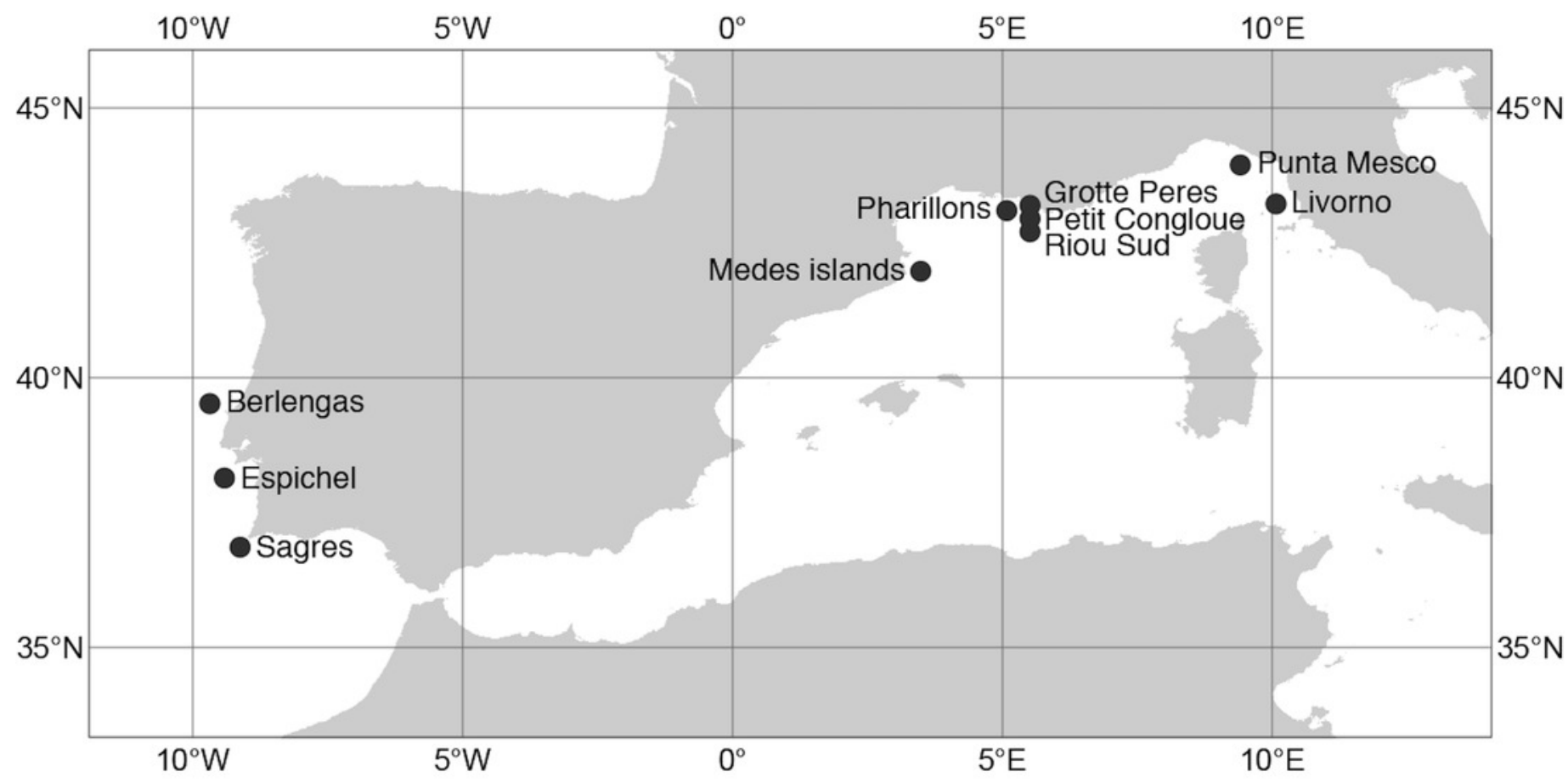




\section{Figure 2}

Genetic diversity (mean \pm SD) as a) allelic richness, b) private alleles and c) expected heterozygosity of Paramuricea clavatain shallow (light grey) and deeper (dark grey) populations.

Asterisks indicate significant differences in diversity levels $(P<0.05)$. Sampling site name, depth $(m)$ and number of samples $(n)$ are described for each population.
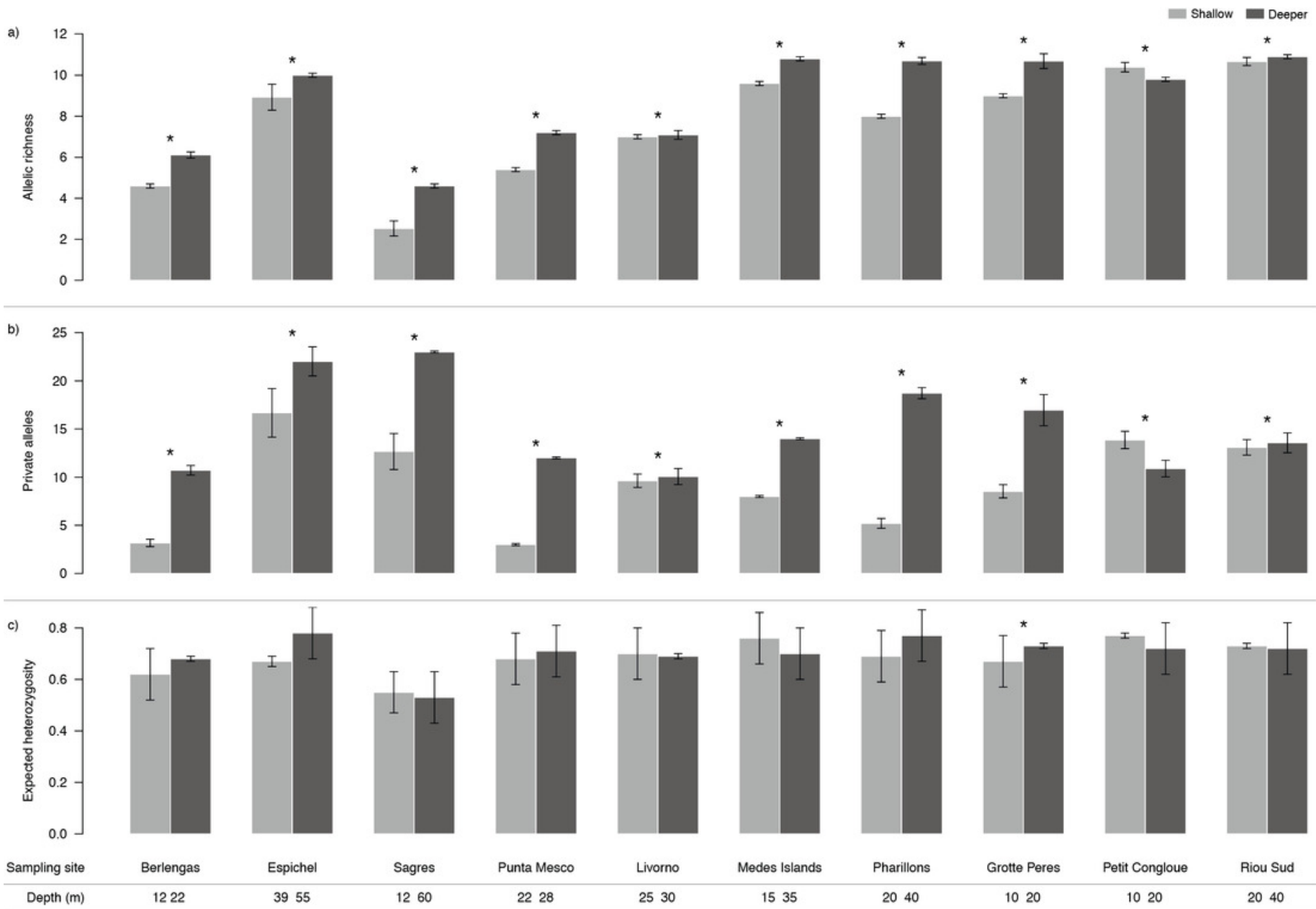

Berlengas

Espichel

Sagres

Punta Mesco

Livorno

Medes Islands

Pharillons

Grotte Peres

Riou Sud

Sample (n)

2830

7232

1810

3030

2530

$27 \quad 27$

2728

2938

3327

2040 
Figure 3

Partial dependence functions depicting the effect of bottom temperature on a) allelic richness, b) private alleles and c) expected heterozygosity.
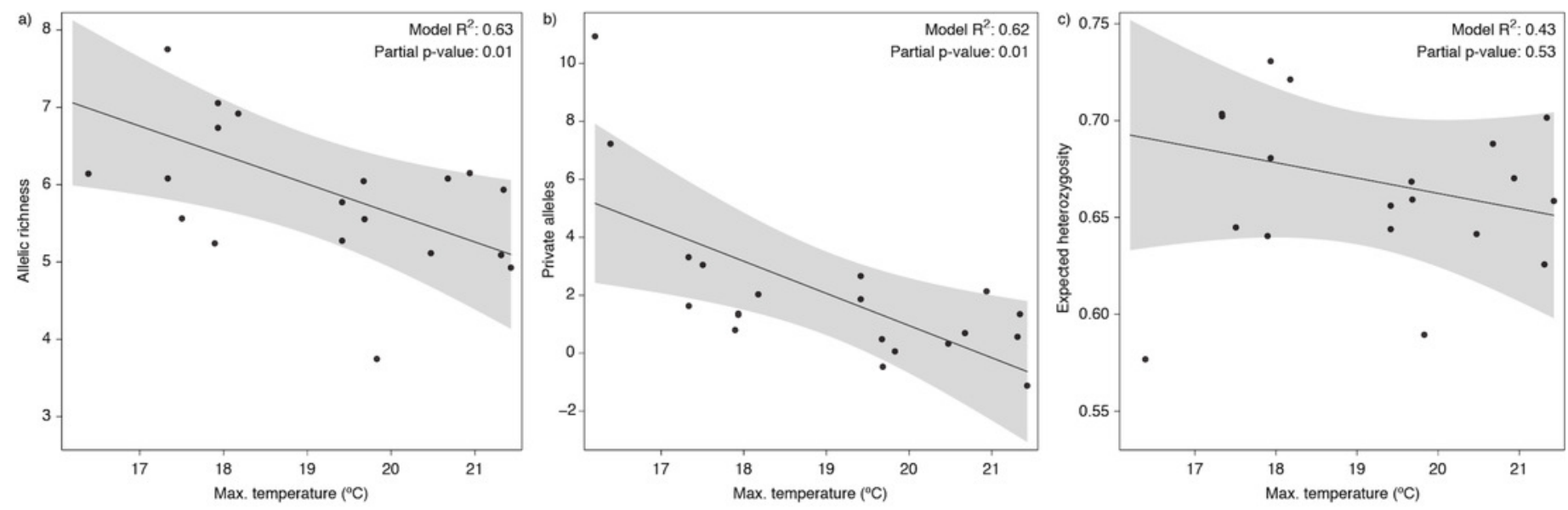
Figure 4

Pairwise genetic differentiation $F_{\mathrm{ST}}$ (mean $\pm \mathrm{SD}$ ) within sampling site (i.e., shallow vs. deeper populations; light grey) and between sampling sites (dark grey).

Asterisks indicate significant differences in genetic differentiation levels $(P<0.05)$.

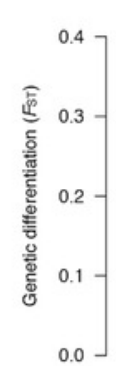

Sampling site

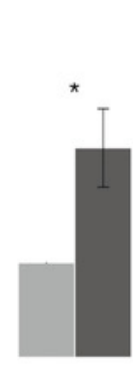

Berlengas

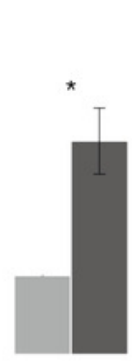

Espichel

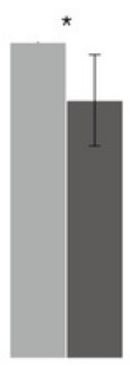

Sagres

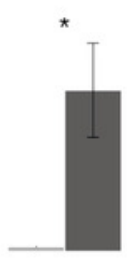

Punta Mesco

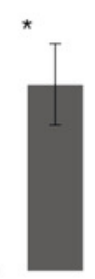

Livorno

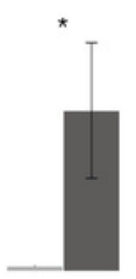

Medes Islands

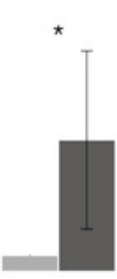

Pharillons
Within region Between regions

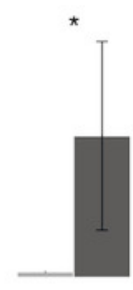

Grotte Peres

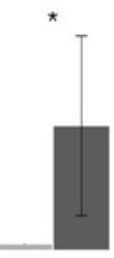

Petit Congloue

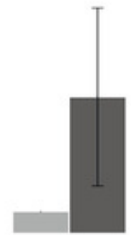

Riou Sud 


\section{Table $\mathbf{1}$ (on next page)}

Summary of linear regression models testing genetic diversity indices against depth and a set of environmental predictors.

Akaike Information Criterion, R-squared and p-value scores are shown for each model. Bold represents higher values when comparisons were made. 


\begin{tabular}{|c|c|c|c|c|c|c|c|c|}
\hline \multirow[b]{2}{*}{ Model type } & \multirow[b]{2}{*}{ Predictors } & \multicolumn{3}{|c|}{ Allelic richness } & \multicolumn{2}{|c|}{ Private alleles } & \multicolumn{2}{|c|}{ Expected heterozygosity } \\
\hline & & AIC & $\mathrm{R}^{2}$ & $\mathrm{p}$-value & AIC $R^{2}$ & $\mathrm{p}$-value & AIC & p-value \\
\hline Null & Depth & 71.05 & 0.22 & 0.01 & 92.840 .60 & 0.01 & -35.260 .01 & 0.77 \\
\hline \multirow[t]{5}{*}{ Environmental } & Model effect & 46.83 & 0.63 & & 74.310 .62 & & -39.330 .43 & \\
\hline & Min. current velocity & & & 0.98 & & 0.45 & & 0.29 \\
\hline & Min. productivity & & & 0.99 & & 0.95 & & 0.81 \\
\hline & Slope & & & 0.72 & & 0.56 & & 0.13 \\
\hline & Max. temperature & & & 0.01 & & 0.01 & & 0.53 \\
\hline
\end{tabular}

1 